ISSN: 2354 - 1431

http://tckh.daihoctantrao.edu.vn/

\title{
Phật giáo trong bối cảnh lễ hội dân gian các nước Đông Nam Á
}

Nguyễn Quang Lê $\hat{e}^{a}$

${ }^{a}$ Viện Nghiên cứu Văn hóa

\section{Article info}

\section{Recieved:}

12/7/2017

Accepted:

03/8/2017

\section{Keywords:}

Buddhism;Southeast Asian; Folklore; Festival.

\begin{abstract}
Buddhism which originated in northern Indian was influenced to mainland Southeast Asian (includes Thailand, Laos, Cambodia, Myanmar and Vietnam) from the early years of A.D. Undergone a long history, Buddhism has deeply influenced the spiritual life as well as on customs of those countries. However, depending on factors of natural environment, society as well as local culture, in each country, Buddhism has shown a flexible approach, adapting itself to different conditions and local ideas. Each nation adopted Buddhism in a unique way according to its national characteristics. Buddhism has assimilated in indigenous religion of host society. The process of indigenization of Buddhism in each country is clearly expressed in a kind of folklore - Folklore Festival in Southeast Asian. This paper focuses on studying Buddhism in context of folklore festivals in mainland Southeast Asian.
\end{abstract}

Phật giáo có nguồn gốc từ Ấn Độ du nhập vào các nước Đông Nam Á (lục địa) như Việt Nam, Lào, Campuchia, Thái Lan và Myanma từ những năm đầu Công nguyên. Trải qua quá trình lịch sử lâu đời, Phật giáo đã ảnh hưởng sâu sắc lên đời sống tâm linh, cũng như lên phong tục tập quán của các nước này. Tuy nhiên, do còn phụ thuộc vào môi trường tự nhiên và xã hội, cũng như đời sống văn hóa vật chất và tinh thần của mỗi dân tộc; mức độ dung hòa của Phật giáo với tín ngưỡng dân gian bản địa, mức độ phong tục hóa và dân gian hóa để trở thành Phật giáo mang sắc thái dân tộc ở mỗi nước có khác nhau. Chính vì lẽ đó, đạo Phật ở các nước kể trên đã mang bản sắc dân tộc và nó ít nhiều biến đổi so với đạo gốc - Phật giáo Ân Độ. Điều đó, được thể hiện rõ nét trong một loại hình sinh hoạt văn hóa dân gian độc đáo Lễ hội dân gian truyền thống của mỗi nước.

Khảo cứu quá trình ảnh hưởng và giao lưu hay nói một cách cụ thể là khảo cứu mối quan hệ của Phật giáo với Lễ hội dân gian truyền thống của các nước Việt Nam, Lào, Campuchia, Thái Lan và Myanma là mối quan tâm chính của tác giả bài viết này.

Lễ hội dân gian truyền thống là một hiện tượng văn hóa xã hội phức hợp, phản ánh tiến trình lịch sử văn hóa của mỗi dân tộc thông qua lăng kính xã hội rất đa dạng và phong phú. Ngay từ khởi thủy, Lễ hội dân gian ở các nước Đông Nam Á phần lớn là lễ hội nông nghiệp do cư dân nông nghiệp tiến hành. Trong đó tín ngưỡng nông nghiệp giữ vai trò chủ đạo, là nguyên nhân và lí do để tiến hành lễ hội dân gian. Do vậy mà người Việt, Lào, Campuchia, Thái Lan và Myanma trên địa bàn Đông Nam Á (lục địa) tổ chức lễ hội theo mùa, như lễ hội mùa Xuân (lễ vào mùa) và Lễ hội mùa Thu (lễ thu hoạch), có nghĩa là trong một năm hay theo một chu trình sản xuất nông nghiệp lúa nước, tổ chức lễ hội theo hai mùa chính: mùa Xuân và mùa Thu (như ở Việt Nam). Điều đó đã chứng tỏ quan niệm về lịch pháp của người Việt, Lào, Campuchia, Thái Lan và Myanma có những nét tương đồng.

Như đã có dịp trình bày, Lễ hội theo quan niệm của chúng tôi thì lễ hội là một tổng thể văn hóa phức hợp gồm có 3 phần: phần Lễ, phần Hội và phần Phong tục, quan hệ tương giao chặt chẽ với nhau trong một chỉnh thể thống nhất ${ }^{1}$. Trong đó phần Lễ có khởi nguyên từ hệ thống tín ngưỡng nguyên thủy và tín ngưỡng dân gian. Vì vậy mà Lễ hội luôn luôn chịu sự ảnh hưởng trực tiếp của các hệ thống tín ngưỡng đó. Đến lượt mình hệ thống tín ngưỡng dân gian cũng không ngừng vận động biến đổi theo tiến trình của lịch sử văn hóa, chịu ảnh hưởng của các yếu tố khác như kinh tế, xã hội, v.v..., trong đó có sự tác động mạnh mẽ và trực tiếp lên tín ngưỡng dân gian (bản địa), đó là sự du nhập vào các nước Đông Nam Á các tôn giáo chính thống, trong đó có Phật giáo. Do vậy, mối quan hệ này làm cho Lễ hội của các dân tộc ở Đông Nam Á không

${ }^{1}$ Xem: Nguyễn Quang Lê, Một số suy nghĩ về nguồn gốc và bản chất của lễ hội cổ truyền dân tộc, Tạp chí: Văn hóa dân gian, số 1-1992, tr.5-10. 
ngừng biến đổi và chính nó là tác nhân chủ yếu tác động lên hệ thống Lễ của Lễ hội phát triển phù hợp với tâm linh của mỗi dân tộc. Về thực chất, mối quan hệ trong đó mang dấu ấn của lịch sử dân tộc, là những tầng, lớp văn hóa mà lịch sử của dân tộc đó hun đúc lên và còn được bảo lưu lại trong một hiện tượng văn hóa dân gian độc đáo - Lễ hội truyền thống. Mối quan hệ giữa Phật giáo với tín ngưỡng dân gian (bản địa) mang tính hai chiều, đó là sự tác động và ảnh hưởng lẫn nhau để cùng nhau thích nghi và tồn tại, cũng như phát triển. Sau khi du nhập vào các nước: Việt Nam, Lào, Campuchia, Thái Lan và Myanma, Phật giáo không chỉ thích nghi và hòa nhập phần nào với tín ngưỡng dân gian, mà còn có quá trình tác động ngược trở lại - chính Phật giáo cũng tác động mạnh mẽ lên tín ngưỡng bản địa, làm cho nó được bổ sung thêm vào nội dung của mình nhiều yếu tố và sắc thái mới.

Bất kì một dân tộc nào, tín ngưỡng dân gian đều có nguồn gốc từ tín ngưỡng nguyên thủy hay tôn giáo sơ khai, và chúng được sản sinh trong lòng xã hội nguyên thủy². Tín ngưỡng dân gian (bản địa) ở các dân tộc nói chung là một hệ thống bao gồm các quan niệm của một cộng đồng hay một dân tộc về thế giới thiên nhiên kì bí xung quanh họ. Mỗi dân tộc đều có một hệ thống tín ngưỡng riêng biệt mang những nét đặc trưng và độc đáo riêng. cho dân tộc đó. Căn cứ vào đấy mà ta có thể phân biệt được dễ dàng các nét đặc thù và bản sắc văn hóa của dân tộc này với dân tộc khác. Tuy nhiên, ta vẫn có thể tìm được một vài nét tương đồng giữa các dân tộc - quốc gia ở Đông Nam Á, vì các quốc gia này có nền văn hóa từ nguồn gốc chung - nền văn hóa Đông Nam Á, hay nói một cách khác, nền văn hóa của các nước nêu trên đều được xây dựng trên nền tảng hoặc cơ tầng văn hóa Đông Nam Á.

Trước hết, ta thấy hệ thống tín ngưỡng nông nghiệp cổ hay hệ thống tín ngưỡng dân gian của người Việt, Lào, Campuchia, Thái Lan và Myanma khá tương đồng, như: các hiện tượng thiên nhiên đầy sức mạnh huyền bí, như mặt trời, mặt trăng, các vì sao, mây mưa, sấm chớp, v.v..., mà trong tâm thức họ coi là đấng siêu nhiên; các vật chất có liên quan đến sản xuất nông nghiệp, như đất, nước, lúa...; các vật linh thiêng (theo thuyết vạn vật hữu linh), như rồng rắn, hổ báo...; các linh hồn của người đã chết như: tổ tiên, ông bà, ma quỷ... Bên cạnh đó còn tồn tại một hệ thống khá phức tạp là những người có khả năng ngoại cảm thực hành tín ngưỡng làm nhiệm vụ giao cảm với thần linh, ma quỷ như: thầy cúng, thầy phù thủy, thầy sa man, thầy bói, v.v... Trong khi đó, lễ hội

\footnotetext{
${ }^{2}$ R.A. Nicolixkia, Nguồn gốc tôn giáo và các hình thức sơ khai của chúng, M. 1968 (tiếng Nga).

+ Xem: X.A. Tocarev, Nhũng hình thức tôn giáo so khai, M. 1964 (tiếng Nga).
}

được dân gian coi như là một phương tiện quan trọng nhằm thỏa mãn lòng mong ước được giao cảm với các vị thần thánh, mà họ tôn sùng. Vì dân chúng vẫn quan niệm rằng: lễ hội là một môi trường đặc biệt mà con người có đủ điều kiện để tiến hành các nghi lễ thờ cúng trang trọng nhất với đấng thần linh mà họ tin rằng có sức mạnh siêu hình tác động lên đời sống con người. Trước khi có sự du nhập của các tôn giáo, trong đó có đạo Phật từ bên ngoài vào, thì hệ thống tín ngưỡng dân gian bản địa vẫn phát triển và biến đổi theo quy luật tự nhiên. Do vậy có thể xảy ra trường hợp một số vị thần thánh nào đó dần bị mất thiêng (theo quan niệm dân gian) và thay vào đó bằng các vị thần linh mới linh thiêng và linh nghiệm hơn. Khi Phật giáo truyền vào các nước Đông Nam Á, thì hệ thống thần linh được bổ sung thêm nhiều nhân tố mới. Những truyền thuyết về thần tích ít nhiều mang tính đạo Phật và những truyền thuyết về đức Phật cũng bị dân gian hóa. Đây là sự hòa đồng, tương tác nhuần nhuyễn của hai hệ thống tín ngưỡng: Phật giáo và tín ngưỡng bản địa, mà sự thể hiện khá rõ nét và sinh động của chúng, ta có thể thấy được trong một dạng lễ hội truyền thống của các dân tộc Đông Nam Á, mà ở Việt Nam dân gian vẫn quen gọi là Lễ hội chùa.

Căn cứ vào các nguồn tư liệu lịch sử, tôn giáo và dân tộc học, thì Phật giáo (Ấn Độ) du nhập vào Việt Nam cách đây gần 2000 năm. Đến thế kỉ VI, Luy Lâu (Thuận Thành, Bắc Ninh) là một trung tâm Phật giáo lớn nhất Việt Nam được sử sách ghi nhận. Đến thời nhà Lý, Phật giáo bước vào giai đoạn cực thịnh và trở thành chính giáo, được nhà nước phong kiến tự chủ ở nước ta trọng dụng. Khi ấy, chùa chiền mọc lên ở khắp làng xã. Giáo lí của đạo Phật tác động mạnh vào nhân sinh quan và thế giới quan, cũng như vào các chuẩn mực đạo đức và thẩm mĩ của người Việt Nam... ${ }^{3}$. Sau khi vào Việt Nam, Phật giáo tự điều chỉnh và tự biến đổi để hòa nhập với tín ngưỡng dân gian. Điều đó đước phản ánh rõ nét trong hệ thống lễ hội cổ truyền. Đó là sự hòa quyện nhuần nhuyễn nhất, mối tương hợp tiêu biểu nhất được thể hiện sống động trong một dạng lễ hội được nảy sinh cùng với nó - Lễ hội chùa.

Ở Việt Nam, bên cạnh những ngôi chùa chỉ thờ Phật, rất phổ biến loại chùa mang tính lưỡng hợp; đó là chùa có cấu trúc "tiền Phật, hậu Thánh/Mẫu", có nghĩa là trong chùa thờ cả Phật lẫn Thánh/Mẫu, loại chùa lưỡng hợp này là sự biểu hiện mối quan hệ tương hợp hữu cơ của Phật giáo với tín ngưỡng dân gian. Ở đây đạo Phật đã chấp nhận các sư tổ (tăng ni hay Phật tử) của mình là

\footnotetext{
${ }^{3}$ Xem: Nguyễn Quang Lê, Tìm hiểu mối quan hệ giữa Lễ hội cổ truyền với Phật giáo qua tín nguõ̃ng dân gian, Tạp chí Văn hóa dân gian, số 4-
} 1992, tr. 71-76. 
những vị Thánh mà người Việt tôn thờ, mà các vị thánh này vẫn mang nội dung của tín ngưỡng dân gian, nhưng dưới hình thức Phật rất độc đáo. Chính vì vậy mà hầu hết các lễ hội chùa lớn ở Việt Nam đều có sự đan xen và hòa quyện của các nghi lễ đạo Phật với các nghi lễ của tín ngưỡng dân gian, bởi các lễ hội này suy tôn và sùng kính đức Phật, cùng các vị thần thánh mang tính lưỡng hợp, vừa là Phật, song lại vừa là thần thánh dân gian. Ta có thể kể một số lễ hội chùa tiêu biểu như: Lễ hội chùa Nành và Lễ hội chùa Láng (Hà Nội), Lễ hội chùa Thầy và Lễ hội chùa Hương (Hà Tây cũ, nay là Hà Nội), lễ hội chùa Dâu và lễ hội chùa Phật Tích (Bắc Ninh), lễ hội chùa Keo (Thái Bình), Lễ hội chùa Phục Lễ (Hải Phòng), Lễ hội chùa Tứ Pháp (Hưng Yên), v.v..., và còn nhiều lễ hội chùa khác ở đồng bằng Bắc Bộ, cũng có mang những tính chất thể hiện rõ mối quan hệ tương giao giữa Phật giáo với tín ngưỡng dân gian của người Việt.

Lễ hội dân gian truyền thống ở Lào cũng rất phong phú, đa dạng, phản ánh khá rõ nét nền văn hóa độc đáo của dân tộc Lào. Từ ngàn xưa, Lào là một nước nông nghiệp, Lễ hội dân gian truyền thống được người Lào gọi là "Bun" - có nghĩa là hạnh phúc, vốn mang nặng sắc thái nông nghiệp, bởi lẽ hạt nhân cơ bản của lễ hội là các nghi lễ nông nghiệp cổ đại. Trong lễ hội các nghi thức và nghi lễ cũng nhằm tôn thờ đấng siêu nhiên có tác động đến mùa màng của người Lào. Họ sử dụng các hình thức để mô phỏng các hiện tượng tự nhiên bằng cách đánh trống thay cho tiếng sấm, đốt pháo thay cho giông chớp, té nước thay cho mưa, v.v..., trong các lễ hội cầu mưa, giống như trong nghi lễ cầu đảo vũ của người Việt. Ở người Lào có tục thả diều (biểu tượng cho mặt trời), tục thả đèn (biểu tượng cho nắng), đắp các núi cát (biểu tượng cho sự khô ráo)... trong các lễ hội cầu nắng. Còn khi cầu được mùa thì họ sử dụng tín ngưỡng phồn thực, là tín ngưỡng cổ nhất biểu tượng cho sự được mùa, sự sinh sôi nẩy nở..., tức là họ dùng các biểu tượng thay cho âm vật và dương vật, hoặc dùng các động tác múa nghi lễ kiểu giao phối âm dương. Bởi vậy trong các lễ hội truyền thống của người Lào, ta thường thấy xuất hiện vật như nước, cát và sợi chỉ đựng trong những chiếc âu nhỏ xinh xắn.

Từ khi du nhập vào Lào, Phật giáo đã tác động trực tiếp lên tín ngưỡng bản địa, nó bổ sung hoặc thay thế một số hạt nhân trong tín ngưỡng dân gian của người Lào. Phật giáo ăn sâu bắt rễ vào đời sống tâm linh của người Lào và trở thành quốc giáo chiếm vị trí độc tôn trong tâm thức dân tộc Lào. Vì vậy trong các lễ hội dân gian của Lào, Phật giáo đã du nhập các nghi lễ và nghi thức, các huyền thoại để giải thích về sự thần kì của các ngày lễ hội. Đó là những câu truyện huyền thoại có liên quan đến đức Phật. Trong các lễ hội tổ chức ở chùa Lào, ngoài các nghi lễ của tín ngưỡng dân gian bản địa còn có các nghi lễ của Phật giáo, chúng đan xen và hòa quyện vào nhau trong một chỉnh thể thống nhất như: ở lễ hội Bun Pi Mây, có các tục hay nghi lễ té nước. Tục ấy trong lễ hội này có hai ý nghĩa, một là nghi lễ cầu mưa (của tín ngưỡng dân gian) và hai là nghi lễ vẩy nước thiêng của Phật giáo. Người Lào thường quan niệm rằng: nhờ có nước mà con người tẩy rửa được mọi bụi bẩn trần gian, hoặc mọi tội lỗi “môn thin", để cho cuộc sống của họ được trong sạch và thanh đạm hơn. Có thể nói Lễ hội Bun Pi mày là ngày hội cầu đảo vũ lớn nhất ở Lào mang tính toàn quốc. Mỗi hình thức sinh hoạt trong lễ hội này đều nói lên sự cầu mong mưa thuận gió hòa, mùa màng bội thu, cầu mong những giọt nước đến tưới mát cho vạn vật, ấm no hạnh phúc cho con người. Song song với việc này, người ta tổ chức đọc kinh niệm Phật trong các chùa, cầu mong đức Phật chứng dám cho những mong ước của chúng sinh và phù hộ cho vụ mùa tươi tốt, nhân khang, vật thịnh.

Campuchia là một quốc gia có nền văn hóa rực rỡ và lâu đời. Những phong tục tập quán, những nghi lễ cộng đồng của người Khmer ngày nay là kết quả của quá trình giao lưu và tiếp biến văn hóa lâu dài giữa nền văn hóa bản địa với nền văn hóa Ân Độ. Có thể nói rằng, bức tranh văn hóa Campuchia là sự dung hòa giữa văn hóa tín ngưỡng nông nghiệp cổ đại (là các nghi lễ chèo thuyền, úp cá...) của người Khmer với văn hóa tôn giáo của Ân Độ, thể hiện qua các nghi lễ thần bí của đạo Bala môn, đạo Hinđu và đạo Phật (tiểu thừa), và những nhân tố văn hóa này giữ vai trò chủ đạo trong lễ hội truyền thống của Campuchia. Ở đất nước này, trong 12 tháng của một năm, không tháng nào là không có lễ hội truyền thống: từ lễ hội mừng mưa xuống, đến lễ hội mừng nước rút để làm mùa; từ lễ dâng áo cho các nhà sư (lễ Cà thân) đến lễ Phchum baal (lễ cúng vong hồn người chết), v.v... Đáng chú ý nhất là Lễ hội Năm mới của Căm puchia được tổ chức từ 13 đến 15 tháng 4 . Trong suốt 3 ngày người ta tổ chức nhiều cuộc tế thần, Phật và vui chơi giải trí, nghỉ ngơi. Chính vì thế nhà sử gia Trung Quốc Chu Đạt Quan đến Campuchia vào khoảng thế kỉ XII có ghi lại như sau: "KhMer tổ chức lễ hội Năm mới vào khee chê êt - tháng nóng nực - Người ta chơi ném còn, kéo co và tập trung tượng Phật ở mọi nơi về tắm rửa cho sạch"4 . Cũng giống như người Lào, người Campuchia tổ chức Lễ Chol Chnăm Th'may (Tết năm mới) truyền thống hàng năm vào giữa tháng 4 , có ý nghĩa như một lễ cầu đảo vũ lớn nhất trong nước. Và cũng từ lâu đời, Phật giáo (tiểu thừa) đã trở thành quốc giáo của Campuchia, nên trong ngày

\footnotetext{
${ }^{4}$ Xem: Phan Hữu Dật (chủ biên), Văn hóa - Lễ hội các dân tộc Đông Nam Á, Nxb. Văn hóa, Hà Nội: 1992, tr.59-60.
} 
hội mọi đức tin đều tập trung vào Phật. Tuy vậy, vẫn không thể thiếu các trò chơi và trò diễn dân gian cổ truyền trong các lễ hội. Nếu như các nghi lễ trong 3 ngày Tết đều gắn chặt với Phật giáo, thì các trò chơi, trò diễn đều gắn liền với dân gian; đó là những trò chơi được nẩy sinh từ lao động sản xuất, từ bao đời nay đã gắn liền với cuộc sống của người dân Campuchia.

Cũng giống như người Việt Nam, Lào, Campuchia, người Thái Lan có một hệ thống tín ngưỡng dân gian bản địa rất phong phú. Họ cũng tôn thờ các đấng thần linh siêu nhiên như: trời, đất, sông, biển, v.v... Đặc biệt trong sản xuất nông nghiệp lúa nước, người Thái cung có quan niệm về lịch pháp giống như người Việt, Lào và Campuchia...

Phật giáo du nhập vào Thái Lan từ rất sớm, khoảng thế kỉ III trước công lịch; vừa mới đặt xong nền móng, đạo Phật đã chứng tỏ là một lực lượng vững chắc, đầy sức thuyết phục, và sẵn sang thích nghi để trở thành quốc giáo chiếm vị trí độc tôn ở Thái Lan. Bởi vậy, nhiều nhà nghiên cứu phương Tây đã gọi Thái Lan là đất nước của chùa tháp, hoặc “đất nước của áo cà sa vàng”. Thật vậy, Thái Lan là một quốc gia mà tuyệt đại đa số dân chúng theo Phật giáo, chiếm gần $90 \%$ dân số. Và đã từ lâu hiến pháp Thái Lan qui định vua phải là Phật tử và Phật giáo đã bám rễ vào mọi mặt cuộc sống của nhân dân. Ở Thái Lan chùa chiền có khắp mọi nơi từ thành thị đến nông thôn. Phật giáo đối với người Thái không phải là những tư tưởng triết học cao siêu về bản ngã và cõi niết bàn, hay về vũ trụ, mà là luân thường đạo lí trong đời sống của chúng sinh. Điều đó chứng tỏ đạo Phật ở đất nước này, đã được dân gian hóa tới mức nào. Người Thái quan niệm rằng, họ làm việc thiện để tích đức cho kiếp sau mới là mục đích sống của con người. Đó là cơ sở để họ quan niệm về "cái thiện" và "cái ác" trong tâm thức của mình. Trên thực tế, Phật giáo đã tác động trực tiếp lên tín ngưỡng bản địa của người Thái, và nó đã ảnh hưởng lên đạo đức, tâm linh và phong tục tập quán của họ. Tuy nhiên, không vì thế mà hệ thống tín ngưỡng dân gian của họ bị mất đi hoàn toàn. Điều này được chứng minh qua một số lễ hội truyền thống tiêu biểu của Thái Lan gắn với tín ngưỡng nông nghiệp cổ đại như: Lễ hội cầu mưa, cầu nắng, hoặc lễ hội cầu mùa..., đến khi Phật giáo đã bắt rễ ăn sâu vào chúng sinh, thì nó ảnh hưởng to lớn lên các lễ hội nông nghiệp này, thậm chí còn lấn át mang đậm sắc thái của đạo Phật, hơn sắc thái dân gian. Ngày nay những lễ hội truyền thống kể trên đều do các nhà sư đứng ra làm chủ lễ, các văn bản Phật giáo (hay các giáo lí) được đọc, được diễn tả như một trò diễn dân gian, và trở thành món ăn tinh thần cho mọi tầng lớp nhân dân. Ở Thái Lan có lễ hội năm mới giống Lào và Cam puchia là lễ hội Song Kran - Hội té nước lớn nhất cả nước; và lễ hội này thường kéo dài từ 3 - 5 ngày (tùy từng nơi), được tổ chức vào khoảng giữa tháng 4. Trong Tết Năm mới người Thái có tục đi lễ chùa và cúng đồ lễ cho các vị sư tăng (là nghi lễ của Phật giáo), còn có tục đốt pháo mừng Năm mới để xua đuổi ma đói, người Thái thường mang cát đến sân chùa để đắp các núi cát (vốn là các nghi lễ dân gian). Đến ngày thứ 3 họ lấy nước thiêng để làm lễ tắm tượng Phật; sau đó khắp nơi tưng bừng hội té nước. Đây chính là lễ tục có nguồn gốc từ tục cầu mưa của cư dân nông nghiệp Đông Nam Á cổ đại.

Lễ hội cầu đảo vũ lớn nhất của người Thái Lan là lễ hội "Bun Bang phay", hay còn gọi là Lễ hội "phóng pháo thăng thiên", được tổ chức vào khoảng giữa tháng 5 đến giữa tháng 6. Lễ hội này mang ý nghĩa cầu mong hạnh phúc phồn thịnh cho mọi nhà, sự sinh sôi nảy nở cho cộng đồng và cho muôn loài. Trong khi các nhà sư tụng kinh ở trong các chùa một cách nghiêm ngặt theo nghi thức của đạo Phật, thì bên ngoài các đám trai gái thanh niên vui đùa nhảy múa, thậm chí họ còn ném các hình dương vật và âm vật vào nhau, cười đùa khúc khích; Hoặc họ còn được thỏa mái uống rượu, thậm chí còn được "tự do" trêu ghẹo nhau ở ngay bên cạnh chùa chiền, mà không bị mắc tội tình gì cả... Tất cả những điều ấy đều biểu hiện rõ nét và sinh động về nghi lễ phồn thực cổ xưa của người Thái Lan trước đây, biểu hiện cho niềm vui và nguyện ước, cầu cho mưa thuận gió hòa, cho mùa màng bội thu, để nhân khang, vật thịnh.

Còn Myanma ngay từ thời thượng cổ, đã nổi tiếng với tên "đất vàng". Đây là một đất nước giàu có về tài nguyên thiên nhiên, đồng ruộng phì nhiêu màu mỡ, động thực vật vô cùng phong phú. Myanma vốn là một nước nông nghiệp, là một trong những vùng có nền văn minh nông nghiệp lúa nước của Đông Nam Á. Vì thế mà người Myanma từ ngàn xưa đã tôn thờ tôn giáo nguyên thủy. Ở mỗi địa phương hoặc trong mỗi gia đình đều thờ các loại ma, mà người ta gọi là "Nát". Người Myanma quan niệm có nhiều loại Nát khác nhau như: nát đất, nát Sông, nát Núi, hoặc nát Lúa... (theo thuyết vạn vật hữu linh). Đến khi Phật giáo du nhập vào Myanma và phát triển mạnh mẽ và trở thành quốc giáo thì việc thờ cúng các Nát giảm dần. Chùa chiền được xây dựng ở khắp mọi nơi từ thành thị đến nông thôn. Vì vậy, Myanma được mệnh danh là đất nước của Phật giáo và chùa vàng; và cũng được biết đến là quê hương của nhiều lễ hội truyền thống nổi tiếng. Người Myanma rất thích và tự hào khi tham gia vào các lễ hội truyền thống của dân tộc mình; vì các lễ hội này thường liên quan ít nhiều đến Phật giáo. Cũng giống như các dân tộc Lào, Campuchia và Thái Lan, người Myanma có tổ chức Tết Năm mới, mà họ gọi là Hội Ti gian (Hội nước), thường được tổ chức vào ngày mồng 1 tháng Dagu 
- tháng 1 (theo lịch Myanma), tức vào nửa đầu tháng 4 Dương lịch. Đây là ngày Tết của cả nước và là ngày hội duy nhất còn lưu giữ được nhiều thuần phong mĩ tục truyền thống của người Myanma. Tiếp theo là Lễ hội Kashoun - Lễ kỉ niệm ngày sinh của đức Phật được tổ chức vào đầu tháng 2 - tháng Kashoun (theo lịch Myanma), tức vào khoảng giữa tháng 5 dương lịch. Trong ngày lễ thường có tục vẩy nước lên các tượng Phật ở các chùa, tưới nước cho các cây bồ đề mà theo truyền thuyết thì đức Phật Thích Ca đã đặc đạo dưới gốc cây này. Ngoài ra ở Myanma còn có nhiều lễ hội khá nổi tiếng như: Lê̂ hội Vajoi tổ chức vào tháng 7 , để kỉ niệm lần giảng đạo đầu tiên của đức Phật về 4 chân lí của Phật giáo...; Lễ hội Tadinijut - "lễ hội đèn" hay "lễ thổi lửa", được tổ chức vào tháng 10 ; Lễ hội Tajanundain tổ chức vào tháng 11 ; Lễ hội Htamane Hto, giống lễ cơm mới ở Việt Nam, tổ chức vào tháng 2 dương lịch, v.v... Về cơ bản, phần lớn các lễ hội truyền thống của Myanma đều ít nhiều liên quan đến Phật giáo, người ta nô nức rủ nhau đi trẩy hội, họ tham gia vào các trò vui chơi tập thể, liên hoan văn nghệ và đi lễ chùa. Đó là những nét đặc trưng của lễ hội truyền thống của Myanma.

Tóm lại, trong lễ hội truyền thống của các dân tộc Đông Nam Á kể trên, các nghi lễ của Phật giáo hòa quyện và đan xen với các nghi lễ của tín ngưỡng dân gian cổ truyền, làm cho Lễ hội ở các nước này mang tính lưỡng hợp: vừa mang đậm đà tính tín ngưỡng dân tộc, vừa mang rõ nét tính Phật giáo. Nét đậm nhạt của mối tương giao này, cũng tạo nên một nét đặc trưng cho Lễ hội truyền thống của các nước Đông Nam Á (lục địa) như đã trình bày ở trên của tác giả bài viết này./.

\section{TÀI LIỆU THAM KHẢO}

1. Toan Ánh, Tín nguõng Việt Nam/Quyển thượng, S.1966;

2. Miến Điện (sách tra cứu), Nxb. "Hayka", M.1982 (tiếng Nga);

3. Tìm hiểu lịch sủ văn hóa Lào, Nxb Văn hóa, H. 1985;

4. Tìm hiểu lịch sủ Lào, T.1 và T.2, Nxb. KHXH, H.1981;

5. Nguyễn Đình Phúc, Vài nét về văn nghệ truyền thống Campuchia, Nxb KHXH, H.1989;

6. Nguyễn Bắc, Tìm hiểu văn hóa nghệ thuật Campuchia, Nxb Văn hóa, H.1984;

7. Phya Anuman Rajadhon, Văn hóa dân gian Thái Lan, Nxb Văn hóa - Viện Nghiên cứu Đông Nam Á, H. 1988;

8. "Thailand in to the 80 s";

9. Nguyễn Bích Liên, Miến Điện, H. 1968;

10. Nguyễn Đình Lễ, Đất nước chùa vàng, H. 1988. 